\title{
RADIOCARBON SAMPLE PREPARATION AT THE CIRCE AMS LABORATORY IN CASERTA, ITALY
}

\author{
Isabella Passariello ${ }^{1,2}$ • Fabio Marzaioli ${ }^{1} \bullet$ Carmine Lubritto $^{1} \bullet$ Mauro Rubino $^{1} \bullet$ \\ Antonio D'Onofrio ${ }^{1} \bullet$ Nicola De Cesare $^{3} \bullet$ Gianluca Borriello $^{1} \bullet$ Giovanni Casa $^{1} \bullet$ \\ Antonio Palmieri ${ }^{1} \bullet$ Detlef Rogalla $^{4} \bullet$ Carlo Sabbarese $^{1} \bullet$ Filippo Terrasi $^{1}$
}

\begin{abstract}
A system with several lines for the preparation of graphite targets for radiocarbon analysis has been built at the new accelerator mass spectrometry (AMS) facility in Caserta, Italy. Special attention has been paid in the design to the reduction of background contamination during sample preparation. Here, we describe the main characteristics of these preparation lines. Results of tests performed to measure ${ }^{14} \mathrm{C}$ background levels and isotope fractionation in several blank samples with the Caserta AMS system are presented and discussed.
\end{abstract}

\section{INTRODUCTION}

In early 2005, a new accelerator mass spectrometry (AMS) system was installed at the Centre for Isotopic Research for Cultural and Environmental Heritage (CIRCE) laboratory in Caserta, Italy, and acceptance tests were completed by the end of February (Terrasi et al. 2007). The system is based on a tandem accelerator 9SDH-2 (built by National Electrostatics Corporation, USA) with a maximum terminal voltage of $3 \mathrm{MV}$. The goal of the facility is to reach a throughput for radiocarbon measurements of more than 1000 samples/yr, and, in the near future, to extend AMS measurements to other isotopes $\left({ }^{10} \mathrm{Be},{ }^{26} \mathrm{Al},{ }^{127} \mathrm{I},{ }^{236} \mathrm{U}\right)$.

At CIRCE, measurements of isotopic ratios ${ }^{14} \mathrm{C} /{ }^{12} \mathrm{C}$ are currently performed for the ${ }^{14} \mathrm{C}$ dating of archaeological samples or in the framework of environmental studies. The typical working conditions are reported below:

- The average ${ }^{12} \mathrm{C}^{-}$current is $30 \mu \mathrm{A}$ from the 40 -sample sputtering ion source, operated with a probe voltage of $6 \mathrm{kV}$, an extraction voltage of $18 \mathrm{kV}$, and a pre-acceleration voltage of $43 \mathrm{kV}$;

- The $45^{\circ}$ spherical electrostatic analyzer is operated at about $\pm 11 \mathrm{kV}$. The $90^{\circ}$ injection magnet vacuum chamber is biased at $\sim 11.4,5.4$, and $0.2 \mathrm{kV}$ for sequential injection of mass 12,13 , and 14 , respectively, with a frequency of $10 \mathrm{~Hz}$;

- The terminal voltage is set at $2.55 \mathrm{MV}$ with a ripple of $0.7 \mathrm{kV}$ peak to peak;

- The Ar stripper pressure is $\sim 10 \mu \mathrm{m} \mathrm{Hg}$, yielding a mean transmission for ${ }^{12} \mathrm{C}^{3+}$ of $52 \%$;

- Analyzed ${ }^{12} \mathrm{C}^{3+}$ and ${ }^{13} \mathrm{C}^{3+}$ currents are measured in offset Faraday cups for 0.25 and $0.8 \mathrm{~ms}$ per cycle;

- Two $45^{\circ}$ electrostatic spherical analyzers are operated at $\pm 40 \mathrm{kV}$;

- The 4-anode ionization chamber is filled with P10 mixture at 50 torr.

The laboratory deals with a variety of sample types such as charcoal, bone, wood, tree rings, peat, shell, foraminifera, soil (paleosols, bulk or fractions of soils), and atmospheric and respired $\mathrm{CO}_{2}$, treated using the standard chemical protocols and graphitized according to 2 different reduction protocols. In order to meet the AMS system potential and to respond to the increasing demand of ${ }^{14} \mathrm{C}$ dating by AMS, the first months of operation of the new lab were dedicated to the development of

\footnotetext{
'Department of Environmental Sciences, Second University of Naples, Caserta, Italy.

${ }^{2}$ Corresponding author. Email: isabella.passariello@unina2.it.

${ }^{3}$ Department of Life Sciences, Second University of Naples, Caserta, Italy.

${ }^{4}$ Institut für Physik mit Ionenstrahlen, Ruhr-Universität Bochum, Bochum, Germany.
} 
new preparation lines and to their characterization in terms of background, fractionation, and contamination. In particular, multireactor preparation lines based on sealed quartz tubes, muffle combustion, and Bosch reaction graphite production have been set, tested, and routinely used for samples with masses $>1 \mathrm{mg}\left(\mathrm{CO}_{2} / \mathrm{H}_{2}\right.$ process). In order to increase the sample preparation throughput, a second line based on the zinc reduction process has been implemented and is presently being characterized. The achievable precision and accuracy were determined through the measurement of blank samples (Aesar graphite) with respect to a reference standard (IAEA C3, cellulose). In order to perform high-precision AMS $(\sigma<0.3 \%)$, it is necessary to introduce a stable (and as low as possible) contamination in the prepared samples and to reach a stable value in the fractionation induced by the preparation lines. This fractionation should be scattered around a mean value with a dispersion comparable to the machine $\delta^{13} \mathrm{C}$ precision ( $\pm 2 \%$ in our case). In the following sections, we discuss the results obtained using the new preparation lines, the preparation background, and the fractionation.

\section{PHASES OF RADIOCARBON SAMPLE PREPARATION}

We have developed 2 different techniques, applying hydrogen and zinc methods, for the sample graphitization in order to produce several samples simultaneously and ensure an increased graphite throughput to match the AMS potentialities.

Before combustion and graphitization, solid samples undergo physical and chemical pretreatments with the aim of contamination removal and/or to isolate the useful carbon fraction. After the physical cleaning by means of sieving, scraping, or ultrasonication, samples are chemically pretreated according to the sample type, i.e.:

- AAA (acid-alkali-acid) protocol for wood, charcoal, and peat (Mook and Streurman 1983);

- Humic acid extraction protocol for paleosoils (Fowler et al. 1986);

- Collagen extraction for bones (Longin 1971);

- $\mathrm{CO}_{2}$ extraction by means of phosphoric acid for carbonates (Hoefs 1987);

- Alpha-cellulose extraction for tree rings (Green 1963).

Pyrex ${ }^{\circledR}$ and glass dishes used in this phase are pre-cleaned ultrasonically and dried in an oven at $120^{\circ} \mathrm{C}$ overnight.

\section{Sample Combustion}

To reduce contamination during combustion, copper oxide $(\mathrm{CuO})$ grains $(\sim 100 \mathrm{mg})$ within quartz tubes are pre-cleaned at $900{ }^{\circ} \mathrm{C}$ in a muffle furnace for $5 \mathrm{hr}$. Unknown samples are weighted according to their expected carbon content percentage, with the aim to obtain about $2 \mathrm{mg}$ of carbon, and finally moved into the pre-cleaned quartz tubes. Each tube is connected to a vacuum line, evacuated via a membrane-turbo pump system at $\sim 2 \times 10^{-4}$ torr, and sealed with a propane oxygen torch. Sealed samples are put in a muffle furnace on an identification refractory brick and combusted at $900{ }^{\circ} \mathrm{C}$ for $5 \mathrm{hr}$. After combustion, the $\mathrm{CO}_{2}$ produced is purified by means of a cryogenic line (see Figure 1) in which the sealed tube is re-evacuated $\left(\sim 2 \times 10^{-4}\right.$ torr) and subsequently cracked in a tube cracker. Combustion gases pass through a water spiral trap (Bertolini et al. 2005), which, partially immersed into a dry ice/ethanol cocktail, removes water vapor. Dry gases are forced through the $\mathrm{CO}_{2}$ spiral trap cooled down by means of its partial immersion in the liquid nitrogen $\left(\mathrm{LN}_{2}\right)$, which traps $\mathrm{CO}_{2}$ in the solid form (sublimation) with $100 \%$ efficiency, avoiding fractionation processes. Small aliquots of incondensable gasses (i.e. thermal nitrogen oxides) are pumped away. Cryogenically purified $\mathrm{CO}_{2}$ from the sample combustion is trapped using $\mathrm{LN}_{2}$ into a calibration volume (pre- 
viously calibrated using elemental analysis standards) and its mass is barometrically determined. About $1 \mathrm{mg}$ of $\mathrm{CO}_{2}$ is finally diverted for graphitization $\left(\mathrm{H}_{2}\right.$ reaction or zinc reaction) and the residual gas is preserved by flame-sealing within 6-mm-outer diameter (OD) Pyrex tubes ready for stable carbon $\left({ }^{13} \mathrm{C} /{ }^{12} \mathrm{C}\right)$ dual-inlet isotope ratio mass spectrometer (IRMS) determination.

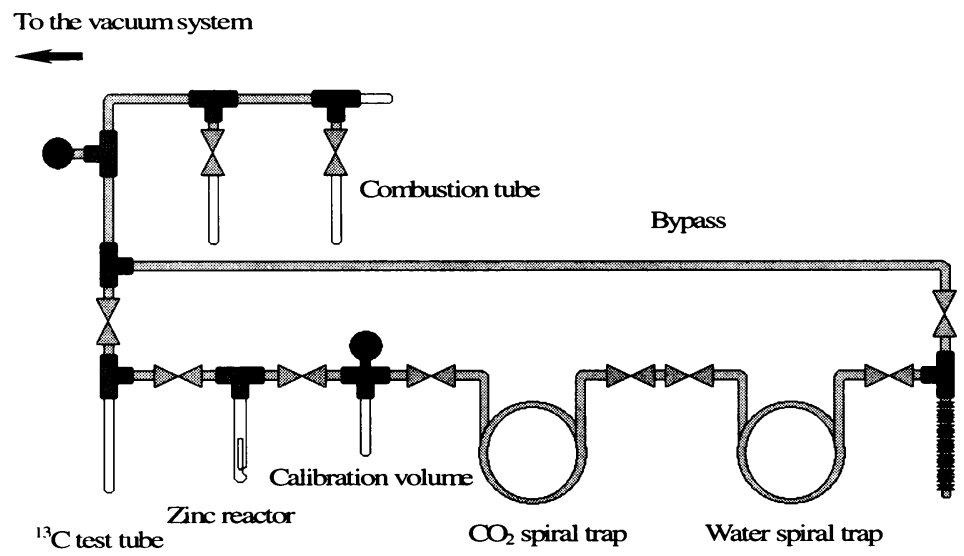

Figure 1 Schematic diagram of the cryogenic line

\section{Graphitization Processes}

The CIRCE preparation lab is equipped with a modular multichamber Bosch hydrogen-reduction graphitization line characterized by a ramp with 4 vessels at the entrance. The -300 mesh (Aesar) Fe powder $\left(2-2.5 \mathrm{mg}\right.$ ) is pre-cleaned at $700{ }^{\circ} \mathrm{C}$ for $10 \mathrm{~min}$ under vacuum and at $700{ }^{\circ} \mathrm{C}$ with hydrogen for an additional $10 \mathrm{~min}$. The quartz tubes used for graphitization are pre-cleaned at $900{ }^{\circ} \mathrm{C}$ for $5 \mathrm{hr}$. The sample $\mathrm{CO}_{2}$ is collected in a glass vessel by means of $\mathrm{LN}_{2}$ and manually transferred to the multi-sample graphitization line $\left(4 \times 10\right.$-mL reaction chambers) built up using modified Parker ${ }^{\circledR}$ high vacuum metal/glass junctions (with Vyton ${ }^{\circledR}$ O-rings) and Louwers ultra-high vacuum stopcocks (Vacutap ${ }^{\circledR}, 8 \mathrm{~mm}$ OD). $\mathrm{CO}_{2}$ samples are sequentially $\mathrm{LN}_{2}$-transferred to each one of these chambers, where the Bosch reaction takes place (Vogel et al. 1984). The $\mathrm{H}_{2}: \mathrm{CO}_{2}$ ratio used in the reaction is $2.5-3: 1$, with a typical reaction time of $4-5 \mathrm{hr}$. During graphitization, the water vapor is removed by using a dry ice/ethanol-cooled cool finger. The multi-sample line is controlled via PC using a graphic control LabVIEW interface, which, together with a vacuum tank reservoir, allows remote control of the vacutaps (see Figure 2).

Graphitization can also be achieved through the zinc reduction process (Jull et al. 1986; Slota et al. 1987; Vogel 1992), in which no $\mathrm{H}_{2}$ is introduced in the line. This preparation method involves less handling and is less time consuming compared to the $\mathrm{CO}_{2} / \mathrm{H}_{2}$ process, but the graphite is expected to be less clean. ${ }^{5}$ The sample $\mathrm{CO}_{2}$, produced by muffle combustion and purified in the cryogenic line (see Figure 1), is transferred to a Pyrex glass tube reactor, torch sealed, and heated on an identification brick at $500{ }^{\circ} \mathrm{C}$ for $4 \mathrm{hr}$ and $530{ }^{\circ} \mathrm{C}$ for an additional $4 \mathrm{hr}$. The zinc reactor is made of a $6-\mathrm{mm}$ OD $\times 80$-mm-length glass vial charged with about $4 \mathrm{mg}$ of -300 mesh (Aesar) Fe powder, placed into another Pyrex glass tube $(9 \mathrm{~mm}$ OD $\times 150 \mathrm{~mm})$ containing $\mathrm{TiH}_{2}$ powder $(\sim 10-15 \mathrm{mg})$ and $\mathrm{Zn}$ powder ( $\sim 30-35 \mathrm{mg}$ ) (Xu et al. 2007). The 6-mm tubes holding the iron powder and 9-mm tubes are pre-cleaned at $500^{\circ} \mathrm{C}$ in a muffle furnace for $3-4 \mathrm{hr}$. The $9-\mathrm{mm}$ tubes are charged with the vacuum

\footnotetext{
${ }^{5}$ After some refinements, this method turned out to be as clean as the other one.
} 


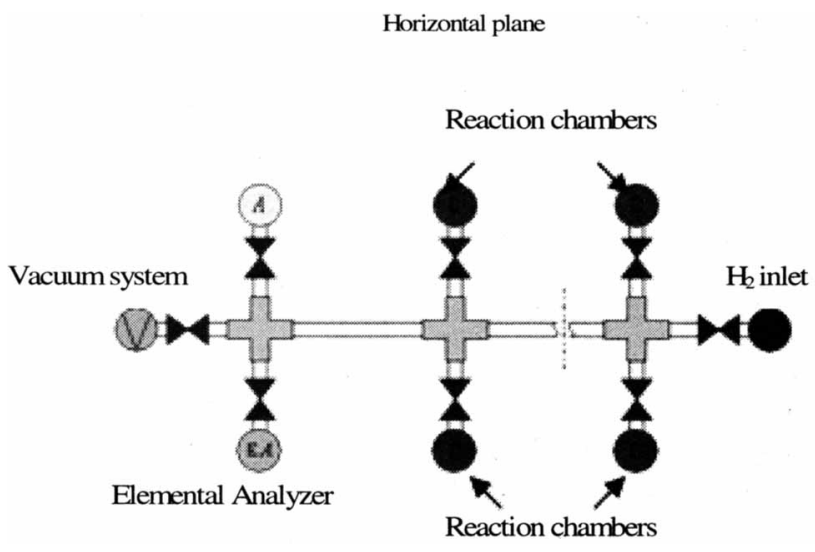

Figure 2 Schematic diagram of the multi-sample line

thermal cleaned $\left(300^{\circ} \mathrm{C}\right) \mathrm{Zn}$ and $\mathrm{TiH}_{2}$, with the 6-mm tubes, and heated at $300{ }^{\circ} \mathrm{C}$ for $3-4 \mathrm{hr}$ before starting the zinc reaction. The graphite obtained is pressed at $150 \mathrm{psi} / \mathrm{cm}^{2}$ into a pre-cleaned (with pure alcohol and acetone) aluminium cathode and then is ready for ${ }^{14} \mathrm{C}$ analysis by our AMS system. No silver powder is added on top of the cathode.

\section{SAMPLE PREPARATION BACKGROUND TESTS}

The new preparation systems described for graphite production have been developed to minimize contamination from modern carbon as a function of sample mass, and thus to have reliable preparative methods with high potential throughputs. We prepared several samples of ${ }^{14} \mathrm{C}$ background (Aesar graphite) and standards using both graphitization procedures: hydrogen $(\mathrm{H})$ and zinc $(\mathrm{Z})$ methods. The graphite produced was pressed in $\mathrm{Al}$ cathode holders with a $\Phi=1-\mathrm{mm}$ hole, and blank samples. ${ }^{14} \mathrm{C} /{ }^{12} \mathrm{C}$ and ${ }^{13} \mathrm{C} /{ }^{12} \mathrm{C}$ ratios were measured in several batches with respect to the IAEA C3 standard. In each batch, a few samples of untreated graphite have also been measured, yielding a typical machine background of $2 \times 10^{-16}$, corresponding to $68,000 \mathrm{yr}$.

For each batch, the cathodes pressed with the material from the same preparation yielded background levels that are not statistically different compared to the uncertainty associated with the single cathode (typically 4\%). On the other hand, the scatter between samples from different preparations, either measured in the same batch or in different batches, indicated a higher variability in the contamination introduced during the sample preparation (about $30 \%$ ).

The results for the samples prepared with the $H$ (hydrogen) procedure are summarized in Table 1 and Figure 3 as apparent ages versus sample mass. In the mass range $>0.5 \mathrm{mg}$, the data show a flat trendline; the apparent age (corresponding to the average value of $\mathrm{pMC}$ ) is $53,300 \mathrm{yr}$ with a standard deviation of the individual results of $2500 \mathrm{yr}$. These values are taken as representative of the background and used to correct data for unknown samples, since all samples treated so far yielded graphite masses of $\sim 1 \mathrm{mg}$ or larger. Blank samples with masses $<0.5 \mathrm{mg}$ indicate an increase in the effect of the contamination introduced by the preparation. We are planning to build a smaller-volume graphitization chamber to improve the background level for submilligram samples.

Rather similar results hold for the $\mathrm{Z}$ (zinc) preparation (see Figure 4), but with a younger average apparent age in the flat part $(45,200 \pm 2000 \mathrm{yr})$ and a larger value of the minimum mass, below which we observe a decrease of the apparent age $(\sim 0.7 \mathrm{mg})$. This could be due to the purity of the 
Table $1 \mathrm{pMC}$ and apparent age of $\mathrm{H}$ (hydrogen) blank samples.

\begin{tabular}{llll}
\hline Sample code & pMC (error) & \multicolumn{2}{c}{ Apparent age yr (error) } \\
\hline DSH35 & $1.08(0.11)$ & 36,348 & $(833)$ \\
DSA838 & $0.34(0.01)$ & 45,740 & $(348)$ \\
DSH37 & $0.16(0.02)$ & 51,562 & $(938)$ \\
DSH36 & $0.14(0.01)$ & 52,916 & $(505)$ \\
DSH38 & $0.19(0.02)$ & 50,371 & $(879)$ \\
DSA839 & $0.23(0.02)$ & $48,910(568)$ \\
DSH43 & $0.14(0.02)$ & $52,530(1230)$ \\
DSH40 & $0.13(0.01)$ & 53,498 & $(502)$ \\
DSH42 & $0.11(0.01)$ & 54,770 & $(547)$ \\
DSH44 & $0.08(0.01)$ & 56,976 & $(605)$ \\
DSH39 & $0.07(0.01)$ & 57,881 & $(661)$ \\
DSH47 & $0.11(0.01)$ & 55,009 & $(478)$ \\
DSH57 & $0.11(0.00)$ & 54,588 & $(306)$ \\
DSH55 & $0.12(0.01)$ & 53,968 & $(703)$ \\
DSH56 & $0.14(0.02)$ & 52,678 & $(703)$ \\
DSH58 & $0.12(0.00)$ & 54,351 & $(326)$ \\
\hline
\end{tabular}

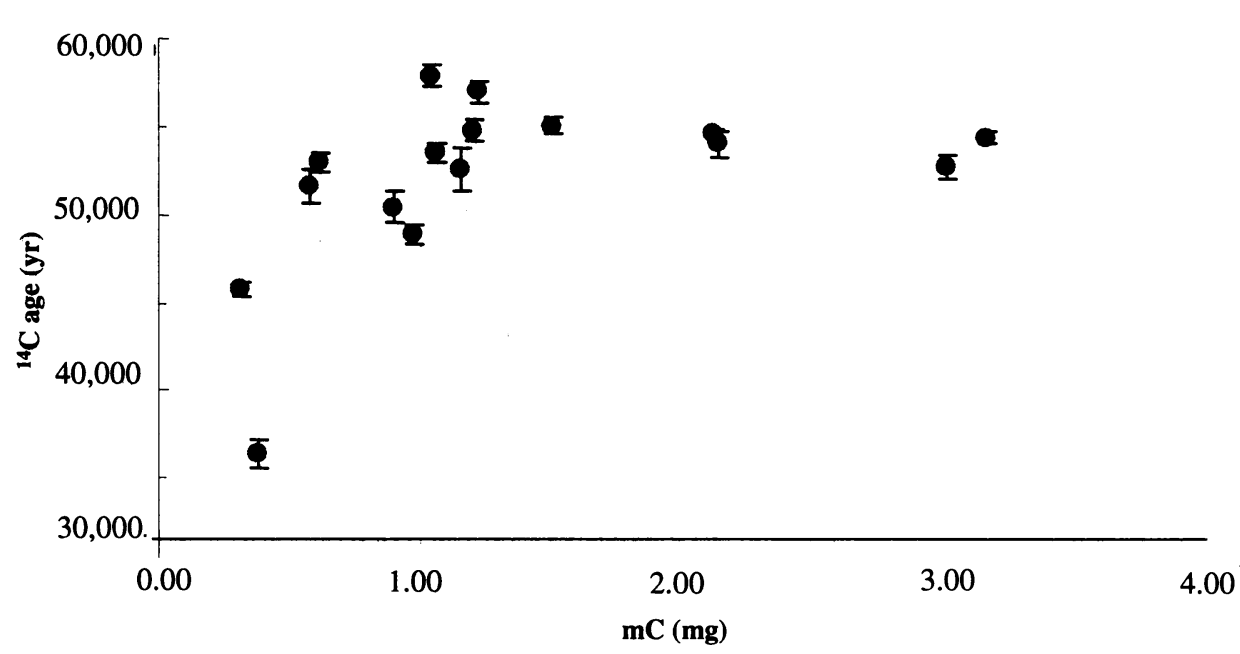

Figure 3 Apparent age of $\mathbf{H}$ (hydrogen) blank samples versus carbon mass (mg). For mass $>0.5 \mathrm{mg}$, we have for all samples an average of apparent age corresponding to $53,300 \pm 2500 \mathrm{yr}$. This value decreases for masses $<0.5 \mathrm{mg}$ due to the larger contamination introduced during sample preparation.

reagents. Work is in progress to improve the purity of reagents so that the contamination introduced is reduced.

\section{FRACTIONATION EFFECTS}

We have investigated the fractionation effects that can occur during combustion, graphitization, and AMS measurement on samples of Aesar graphite, characterized by $\delta^{13} \mathrm{C}$ and ${ }^{14} \mathrm{C}$ analyses. The $\delta^{13} \mathrm{C}$ of the untreated graphite used for blank sample preparation was measured using an elemental analyzer (EA) coupled to an isotope ratio mass spectrometer (IRMS). In the second and third column of 


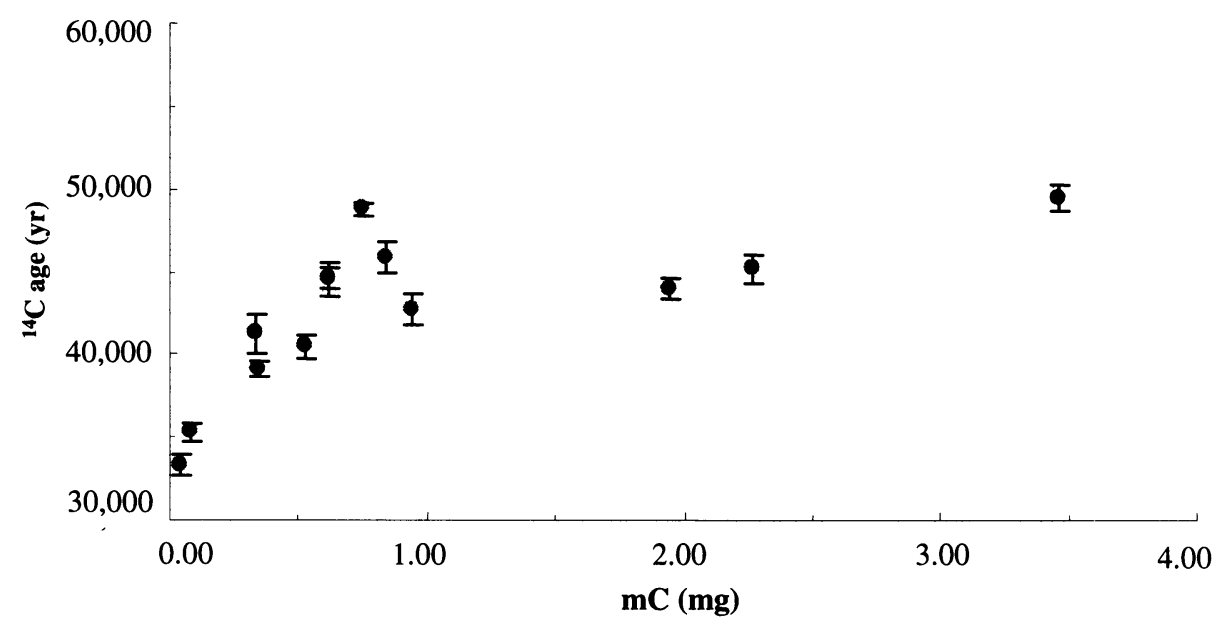

Figure 4 Apparent age of $Z$ (zinc) blank samples versus carbon mass (mg). For masses $>0.7 \mathrm{mg}$, we have for all samples an average of apparent age corresponding to 45,200 $\pm 2000 \mathrm{yr}$. We observe a decrease of this value already for masses $<0.7 \mathrm{mg}$.

Table 2, the results (vs. PDB) are presented as an arithmetic mean of the values obtained with several samples, with the standard deviation of the set of data.

Graphite samples have been combusted and graphitized with both the $\mathrm{H}$ and $\mathrm{Z}$ methods described above: combusted sample $\mathrm{CO}_{2}$ was used for determining (via dual-inlet) ${ }^{13} \mathrm{C} /{ }^{12} \mathrm{C}$ ratios using the IRMS; the graphitized samples were used for determining the ${ }^{13} \mathrm{C} /{ }^{12} \mathrm{C}$ ratio by EA/IRMS. The corresponding $\delta^{13} \mathrm{C}$ values are reported in columns 4-7 in Table 2. All these fractionations are determined with respect to gaseous and/or solid standards routinely used in stable isotope analysis. The standard deviations of the measurements on the combusted samples are the same as those usually found for the respective isotopic ratio measurement procedures, indicating that the variability of the combustion-induced fractionation is negligible, within the error, while the comparison of absolute values shows a small fractionation at the level of $2 \sigma$.

Table $2 \delta^{13} \mathrm{C}$ of Aesar blank samples measured at different stages of preparation for $\mathrm{H}$ (hydrogen) and $\mathrm{Z}$ (zinc) lines. The IRMS measurements on graphitized samples show a larger scatter with respect to the untreated ones due to the graphitization procedures, which introduce a statistically significant scatter in fractionation. This effect is larger for the $\mathrm{Z}$ preparation (EA = elemental analyzer; IRMS = isotope ratio mass spectrometer).

\begin{tabular}{lllllllll}
\hline & Untreated & & \multicolumn{2}{c}{ Combusted } & \multicolumn{3}{c}{ Graphitized } & \multicolumn{3}{c}{ Graphitized } \\
& EA+IRMS & St dev & IRMS & St dev & EA+IRMS & St dev & AMS & St dev \\
\hline H line & \multirow{2}{*}{20.7} & \multirow{2}{*}{0.2} & -21.16 & 0.01 & -21.7 & 0.6 & -21.6 & 1.8 \\
Z line & & & -21.15 & 0.01 & -25.4 & 2.6 & -19.6 & 4.2 \\
\hline
\end{tabular}

The IRMS measurements on graphitized samples show a larger scatter with respect to the untreated ones. This suggests that the graphitization procedures introduce a statistically significant scatter in fractionation, the effect being larger for the $\mathrm{Z}$ preparation. The average absolute values of $\delta^{13} \mathrm{C}$ after graphitization are slightly more negative than the $\mathrm{CO}_{2}$ resulting from combustion, at the level of $1 \sigma$ and $1.6 \sigma$ for the $\mathrm{H}$ line and $\mathrm{Z}$ line, respectively. For the $\mathrm{H}$ line, both the shift and its standard deviation are below the average precision in the ${ }^{13} \mathrm{C} /{ }^{12} \mathrm{C}$ ratio measured on-line during AMS runs 
$(\sim 2 \%$ ). The results of the latter measurements on the same samples are shown in the last 2 columns of Table 2. It has to be noted that the on-line $\delta^{13} \mathrm{C}$ values are determined with respect to a $\mathrm{C} 3$ standard graphitized with the same procedure. For the $\mathrm{H}$ line measurements, we conclude that both the machine- and preparation-induced fractionation is canceled out by the normalization procedure, and that the fractionation correction of the ${ }^{14} \mathrm{C} /{ }^{12} \mathrm{C}$ ratios is properly applied (Bronk Ramsey et al. 2004; Steier et al. 2004).

The situation is different for the $\mathrm{Z}$ line data, where the poorer reproducibility of the fractionation introduced by the graphitization procedure is indicated by the standard deviation in column 7 , which is larger than the reproducibility of the AMS $\delta^{13} \mathrm{C}$ measurements for constant preparation fractionation. This is confirmed by the data in the last 2 columns of Table 2 , where the standard deviation results from the convolution of the dispersion in the material fractionation and the instrumental precision. We then expect that the fractionation correction to the ${ }^{14} \mathrm{C} /{ }^{12} \mathrm{C}$ ratios will still properly take into account the effects of graphitization, but it will result in a larger uncertainty in the final result, and in a biased result for the sample $\delta^{13} \mathrm{C}$ value. Another feature we have observed in the AMS measurements on samples prepared with the $\mathrm{Z}$ line with respect to the $\mathrm{H}$ line is a larger variability in the source yield, which again could affect the precision in the measured isotopic ratios.

\section{CONCLUSION}

The $2{ }^{14} \mathrm{C}$ sample preparation lines established at the CIRCE laboratory in Caserta have been described, and tests on the preparation-induced background and fractionation have been discussed on the basis of extensive tests. The line based on muffle combustion and graphitization in a multireactor line produced samples of mass $>1 \mathrm{mg}$ characterized by negligible fractionation effects and an apparent age for blank samples corresponding to 53,300 yr with a standard deviation of $2500 \mathrm{yr}$. For the mass range $>1 \mathrm{mg}$, the line is utilized for routine measurements of unknown samples; systematic checks on secondary standards included in each measurement batch indicate that an accuracy $<0.3 \%$ is achieved for modern samples in normal operation (Terrasi et al. 2007). Measurements on submilligram samples will be included in routine analyses as soon as the tests on a newly designed small-volume graphitization line are implemented.

Optimization of a separate line based on the zinc reduction method is underway and, when completed, will significantly improve the throughput of the laboratory. At the present time, samples prepared with the $\mathrm{Zn}$ method appear to show sizeable effects on the precision of the isotopic ratios measurements, so that we need further improvements in the preparation procedure before using these samples in routine high-precision AMS measurements.

\section{REFERENCES}

Bertolini T, Rubino M, Lubritto C, D'Onofrio A, Marzaioli F, Passariello I, Terrasi F. 2005. Optimized sample preparation for isotopic analyses of $\mathrm{CO}_{2}$ in air: systematic study of precision and accuracy dependence on driving variables during $\mathrm{CO}_{2}$ purification process. Journal of Mass Spectrometry 40(8):1104-8.

Bronk Ramsey C, Higham T, Leach P. 2004. Towards high-precision AMS: progress and limitations. Radiocarbon 46(1):17-24.

Fowler AJ, Gillespie R, Hedges REM. 1986. Radiocarbon dating of sediments. Radiocarbon 28(2A):44150.

Green JW. 1963. Wood cellulose. In: Whistler RI, editor.
Methods of Carbohydrate Chemistry. New York: Academic Press. p 9-21.

Hoefs J. 1987. Stable Isotope Geochemistry. 3rd edition. Berlin: Springer-Verlag. 241 p.

Jull AJT, Donahue DJ, Hatheway AL, Linick TW, Toolin LJ. 1986. Production of graphite targets by deposition from $\mathrm{CO} / \mathrm{H}_{2}$ for precision accelerator ${ }^{14} \mathrm{C}$ measurements. Radiocarbon 28(2A):191-7.

Longin R. 1971. New method of collagen extraction for radiocarbon dating. Nature 230(5291):241-2.

Mook WG, Streurman HJ. 1983. Physical and chemical aspects of radiocarbon dating. PACT 8:47-53.

Slota Jr PJ, Jull AJT, Linick TW, Toolin LJ. 1987. Prep- 
aration of small samples for ${ }^{14} \mathrm{C}$ accelerator targets by catalytic reduction of CO. Radiocarbon 29(2):303-6.

Steier P, Dellinger F, Kutschera W, Priller A, Rom W, Wild EM. 2004. Pushing the precision limit of ${ }^{14} \mathrm{C}$ AMS. Radiocarbon 46(1):5-16.

Terrasi F, Rogalla D, De Cesare N, D'Onofrio A, Lubritto C, Marzaioli F, Passariello I, Rubino M, Sabbarese C, Casa G, Palmieri A, Gialanella L, Imbriani G, Roca V, Romano M, Sundquist M, Loger R. 2007. A new AMS facility in Caserta/Italy. Nuclear Instruments and Methods in Physics Research B 259(1):14-7.

Vogel JS. 1992. Rapid production of graphite without contamination for biomedical AMS. Radiocarbon 34(3):344-50.

Vogel JS, Southon JR, Nelson DE, Brown TA. 1984. Performance of catalytically condensed carbon for use in accelerator mass spectrometry. Nuclear Instruments and Methods in Physics Research B 5(2):289-93.

$\mathrm{Xu}$ X, Trumbore SE, Zheng S, Southon JR, McDuffee KE, Luttgen M, Liu JC. 2007. Modifying a sealed tube zinc reduction method for preparation of AMS graphite targets: reducing background and attaining high precision. Nuclear Instruments and Methods in Physics Research B 259(1):320-9. 